\title{
Análisis cuantitativo en los informativos de televisión: un modelo para la categorización del ‘Gaur Egun’ de ETB-Televisión Vasca
}

\author{
José María PASTOR GonZÁlez \\ Universidad del País Vasco (UPV/EHU) \\ josemari.pastor@ehu.es
}

Recibido: 25 de agosto de 2013

Aceptado: 20 de enero de 2014

\begin{abstract}
Resumen
Este artículo aborda los diversos aspectos de la categorización en la investigación cuantitativa aplicada al análisis de un informativo de televisión. El proceso de creación de estas categorías y sub-categorías y la definición de cada uno de esos conceptos constituyen el eje central del trabajo. Para ello, se ha tomado como base el programa Gaur Egun de ETB-Televisión Vasca y se ha diseñado un sistema de categorías específico en el cual se han clasificado las unidades de información que componen la muestra.

Palabras clave: investigación cuantitativa, noticias, categorización, ETB
\end{abstract}

\section{Quantitative analysis in television news: a model for categorizing the news of ETB-Basque Television's 'Gaur Egun'}

\begin{abstract}
This article discusses the various aspects of categorization in quantitative research applied to the analysis of television news. The process of creating these categories and sub-categories and the definition of each of these concepts are the main topics of this work. The research is based on the news broadcasted by ETB-Basque Television in its program Gaur Egun. For this purpose, it was designed a system of categories in which the author classifies the information units used in the sample.
\end{abstract}

Keywords: quantitative research, news, categorization, ETB

\section{Referencia normalizada}

PASTOR GONZÁLEZ, José María (2014): “Análisis cuantitativo en los informativos de televisión: un modelo para la categorización del 'Gaur Egun' de ETB-Televisión Vasca”. Estudios sobre el Mensaje Periodístico. Vol. 20, Núm. 2 (julio-diciembre), págs.: 805-819. Madrid, Servicio de Publicaciones de la Universidad Complutense.

Sumario: 1. Introducción. 2. Metodología; 2.1. Universo; 2.2. Elección de la muestra; 2.3. Unidad de información (UI). 3. Sistema de categorías; 3.1. Categorización en el análisis cuantitativo; 3.2. Prueba de fiabilidad; 3.3. Elección de la muestra. 4. Creación y desarrollo de las categorías; 4.1. UI y secciones del informativo; 4.2. UI: tipos y características; 4.3. Categorización de la territorialidad; 4.4. Protagonistas políticos. 5. Conclusiones. 6 . Referencias bibliográficas.

\section{Introducción}

Este trabajo pretende ser una aportación al análisis cuantitativo de los contenidos de los informativos televisivos. En él se describen la metodología seguida y las diferentes categorías que el autor ha creado a la hora de estudiar los espacios informativos emitidos por ETB (Euskal Telebista-Televisión Vasca), así como su aplicación en esta investigación. El informativo de la ETB Gaur Egun, noticiero en lengua vasca emitido por la noche, es el campo en el que se han aplicado estas categorías, el ámbito del que se ha extraído el universo que ha servido como base para este trabajo. 
El objeto de la investigación ha sido comparar la información política vasca que dicho programa difundió durante los mandatos de los lehendakaris Juan José Ibarretxe (PNV) y Patxi López (PSE-EE). El foco se centra en el análisis de contenido del informativo Gaur Egun, tomando como base los años 2008 y 2010. El primero de ellos se corresponde al período en el que Ibarretxe era lehendakari de la Comunidad Autónoma Vasca; el segundo se ubica ya en el mandato de Patxi López. Para ello se han utilizado los dos modelos de investigación propios de este tipo de análisis: el cualitativo y el cuantitativo.

Por medio del análisis cualitativo se establecen las bases y características de los contenidos difundidos en ese informativo, así como las razones por las cuales se han elegido determinados hechos informativos en detrimento de otros. Los grupos focales y las entrevistas en profundidad realizadas aportan elementos de juicio para poder discernir estos motivos.

Por su parte, el análisis cuantitativo de este trabajo se realiza mediante un sistema deductivo en el que el investigador ha establecido primero el marco teórico. Tras decidir realizar el análisis de contenido, el investigador determina qué material utilizará y en que unidades de análisis desarrollará su trabajo. El siguiente paso será crear las categorías que posteriormente codificará. Mediante estas categorizaciones clasifica y ordena los contenidos informativos del noticiero. Estas categorías se encuentran a su vez divididas en sub-categorías, cada una de las cuales sirve para clasificar de modo inequívoco la unidad de información objeto de análisis.

La categorización surge de una reflexión previa que aporta las bases para poder clasificar con nitidez a posteriori las unidades de información presentes en los contenidos del informativo Gaur Egun. Un análisis de la tipología de las noticias incluidas habitualmente dibuja un espectro de categorías óptimas para ordenar los datos recabados, y presenta también un grupo de sub-categorías para cada uno de los compartimentos creados.

\section{Metodología}

El análisis de contenido ha sido el instrumento elegido a la hora de llevar a cabo la investigación cuantitativa de este trabajo. Este tipo de metodología sirve para clasificar y analizar los contenidos informativos que aparecen en los medios (Zabaleta, 1997:187): "El análisis de contenido, entendido como un tipo de metodología cuantitativa, es un compendio de técnicas empleadas para analizar las comunicaciones. Por consiguiente, puede analizar cualquier contenido comunicativo". Este proceso exige objetividad y concisión, ya que el éxito del mismo depende del rigor de la categorización (Berelson, 1962: 147): "El análisis de contenido se sustenta o se cae por sus categorías".

\subsection{Universo}

El universo de este trabajo de investigación está compuesto por todas las unidades de información de los informativos de la edición nocturna de Gaur Egun de los dos años mencionados. En el año 2008 abarca desde el uno de enero al 31 de diciembre; en el 2010 del uno de enero 30 de diciembre. En el primer año se emitieron un total de 366 
noticieros en esa franja horaria -fue año bisiesto-; en el segundo, 365. En total se han analizado 1.262 unidades de información (UI): 552 correspondientes al año 2008 y 710 tomadas de los informativos del 2010.

\subsection{Elección de la muestra}

Para seleccionar la muestra en la que basar el análisis de contenido del informativo Gaur Egun se ha utilizado la metodología de la semana compuesta. De esta manera se ha podido extraer una muestra que puede representar de una manera fidedigna el universo de los informativos y sus contenidos (Zabaleta, 1997: 154): "En la investigación científica, con frecuencia, se elige de un universo claramente definido una muestra que, mediante un proceso concreto, resulta representativa de ese universo. La palabra representativa es de vital importancia, ya que el valor de la muestra reside precisamente en ello, en el hecho de sustituir al universo".

En su trabajo para crear un modelo válido para el análisis de informativos, Riff y otros investigadores analizaron qué tipo de muestra era la más adecuada para el análisis de contenido de los informativos de televisión, así como el tamaño de esta. En ese proceso de investigación examinaron los informativos que las cadenas estadounidenses ABC y CBS emitieron en el año 1992, tomando como base una semana de cinco días, de lunes a viernes. En total de analizaron tres modelos de muestras:

1) Muestra aleatoria simple: Muestras de un tamaño de 5, 10, 15, 20, 25, 30, 35 y 40 días. Para cada uno de estos tamaños se prepararon 40 muestras diferentes.

2) Muestra estratificada por meses: Esta muestra tiene un tamaño de 24 días. Por cada mes se eligieron dos días aleatoriamente. En total, se compuso un conjunto de 40 muestras diferentes.

3) Semana compuesta: Cuatro semanas para todo el año y, por consiguiente, una semana por trimestre -informativos de lunes a viernes, cinco días por semana-; 20 días en total con un conglomerado de 40 muestras diferentes.

En este estudio se ha utilizado la muestra de la semana compuesta desarrollada a través de un período de tiempo quincenal. Los años elegidos como espacio temporal de referencia para realizar la investigación han tenido una muestra total de 49 días: 24 días con 24 informativos nocturnos en el año 2008 y 25 Gaur Egun en el 2010. La muestra ha tomado los siete días de la semana como base, de lunes a domingo. Las unidades de información analizadas provienen de los programas informativos que constituyen las muestras de los dos años en cuestión.

La investigación se ha iniciado partiendo del primer lunes de la primera semana del año, para proseguir con los días siguientes de la semana, pero en paréntesis o saltos de dos semanas y un día, es decir, con una periodicidad quincenal. Por ejemplo: el primer día de la muestra del año 2008 es el lunes 7 de enero. El segundo, el martes 22 del mismo mes, es decir, dos semanas (14 días) y un día más tarde. El siguiente día, miércoles, se corresponde con el seis de febrero. Así sucesivamente hasta completar los siete días de la semana siempre con un intervalo o periodicidad quincenal. 


\subsection{Unidad de información (UI)}

Los informativos de televisión tienen una estructura propia, pero las características de esta no difieren mucho de las de otros medios de comunicación. La estructura de los informativos diarios guarda similitud con la de los informativos de la radio. Tiene varios apartados: inicio, titulares, desarrollo o corpus y cierre. Esas cuatro partes de la estructura del informativo se encuentran encadenadas en la escaleta, que sería como el guión del noticiero con un minutado. La escaleta muestra la composición del informativo con su orden jerárquico; nos indica la duración de las unidades de información y el orden en que están dispuestas; dónde está ubicado cada elemento, delante y detrás de qué otra unidad de información. Al fin y al cabo, el orden es también, junto con la duración de la noticia, un componente importante que nos informa de la relevancia de un suceso o, mejor dicho, de la importancia que un determinado medio de comunicación, por medio de un informativo, otorga a ese suceso. Este modelo es inherente al mensaje periodístico, tanto en los medios audiovisuales como en la prensa escrita:

"El modelo es la representación cognitiva crucial que los comunicadores (tanto periodistas como lectores) utilizan para comprender los acontecimientos y las situaciones informativas. Este es también el modelo que el periodista desea transmitir a los lectores a través de las informaciones periodísticas. Y las estructuras de esta información periodística están organizadas de manera tal que el modelo propuesto pueda efectivamente comunicarse: lo que ocupa un lugar alto en la jerarquía del modelo también aparecerá en un nivel alto en la jerarquía estructural del texto periodístico, en los titulares o en el encabezamiento" (Dijk, 1990: 256-257).

Esto también sucede en el orden que se establece para las noticias incluidas dentro de las secciones que conforman la estructura del informativo, tal y como afirma Rosa Martín Sabaris en su tesis doctoral La organización informativa y los procesos de producción de la noticia. La información diaria en Euskal Telebista:

"Como norma general, puede decirse que la importancia decrece a medida que avanza el informativo, y que esto es así tanto para cada noticia aislada como para la disposición de las secciones dentro del programa. Se yuxtaponen así dos criterios para la colocación de las noticias en el guión: uno que clasificaría las secciones según su importancia (cultura es menos importante que política y, por consiguiente, se emite más tarde) y otro que ordenaría los temas dentro de la sección" (Martín Sabarís, 1999: 313).

La unidad mínima del análisis de contenido de este trabajo de investigación es la unidad de información (UI). La UI es una pieza informativa independiente compuesta por elementos orales e icónicos propios del medio audiovisual, presentada en diversos formatos, con introducción del presentador del informativo o sin ella.

La unidad de información se encuentra insertada en el corpus del informativo, bien diferenciada de las otras UI. El corpus es el núcleo del noticiero, el espacio en el que se difunden ya completamente desarrolladas todas las noticias. Se encuentra situado entre los titulares y la despedida. Su información se distribuye en secciones.

El corpus, como centro del informativo, y su composición suponen la base de este estudio, puesto que son las unidades de información contenidas en esta parte del no- 
ticiero las que se han contabilizado en la investigación. Pese a ello, también se ha analizado si estas UI aparecen en los titulares del informativo, ya que este dato suele revelar la importancia que se le da al contenido de una noticia determinada.

Las unidades de información agrupadas en el corpus de cada informativo son producciones informativas unidas a determinados hechos noticiables. Aunque esa producción informativa nos sea presentada como un proceso objetivo e imparcial, la realidad es otra (Hartley 1992: 78): "La noticia ha de ser imparcial; esto es, debe narrar acontecimientos sin un punto de vista. Como eso es imposible, existe una contradicción entre la (requerida) imparcialidad y el (inevitable) punto de vista". Por eso mismo se puede decir que toda emisión informativa en televisión se basa en un elemento valorativo (Martin Serrano, 1981: 43): "(la televisión)... interviene en la valoración de la realidad tanto por sus juicios de valor explícitos, como por la valoración implícita que lleva a cabo sobre los temas que aparecen en la pequeña pantalla".

En ocasiones, un suceso que se ha convertido en noticia generará una única UI. Por el contrario, otras veces una misma noticia será fuente de varias unidades de información. Algunas noticias y unidades de información emitidas en el informativo del 18 de junio del 2010 constituyen un claro ejemplo de esto. Ese día una de las noticias principales era el cierre de los servicios nocturnos de urgencias en algunos ambulatorios del País Vasco y así aparecía en la escaleta. En este caso, ese suceso es la unidad de información a. A continuación le sigue otra UI relacionada con el mismo tema. La tercera unidad de información nos habla de la visita del investigador lingüístico George Lakoff a Bilbao. La siguiente UI de la escaleta tiene como tema principal a las mujeres que en el País Vasco visten el velo islámico:

a) Cierre de los ambulatorios.

b) Encuesta a los ciudadanos sobre esta decisión.

c) George Lakoff en Bilbao.

d) Mujeres con velo islámico.

La unidad de información a y la unidad de información $\mathbf{b}$ son independientes en lo que a su formato se refiere. Se trata de piezas perfectamente separadas y diferenciadas: una es una noticia que incluye una conexión en directo con un periodista y la otra una encuesta realizada a los ciudadanos de a pie acerca de la decisión tomada por el departamento de sanidad del Gobierno vasco. Por el contrario, las unidades c y d son totalmente independientes, no solo en su presentación sino también en lo que se refiere al contenido informativo de ambas, ya que no tienen nada que ver la una con la otra.

\section{Sistema de categorías}

El análisis de contenido es un instrumento esencial para identificar y clasificar las particularidades más representativas de las unidades de información examinadas (Holsti, 1969:14): "Se trata de cualquier técnica para inferir identificando objetiva y sistemáticamente las características específicas de los mensajes". Categorizar no es sino nombrar de manera inequívoca el contenido que se está analizando; dotar de un nombre a esa informativa expuesta en la unidad de análisis. 
A la hora de diseñar las bases para el análisis cuantitativo es fundamental preguntarse por qué se crean determinadas categorías y sub-categorías, y en qué sustento teórico se apoyan. Ello nos llevará a una definición concreta de cada una de ellas, que se basará en la exclusividad: una misma unidad de información objeto de análisis no podrá encontrarse en dos sub-categorías a la vez (Galeano Marín, 2004: 14): "La mutua exclusión de los componentes del sistema categorial tiende a eliminar las redundancias y la desorientación a la hora de clasificar los datos".

\subsection{Categorización en el análisis cuantitativo}

El análisis del informativo se ha realizado en doce categorías, divididas a su vez en sub-categorías. Se ha considerado que estos grupos recogen conceptos esenciales que pueden ayudar a detectar las diferencias en el tratamiento de la información política vasca en los Gaur Egun de ETB en los años en que Ibarretxe y López fueron lehendakaris de la Comunidad Autónoma Vasca. Así pues, las doce categorías establecidas y definidas para este trabajo son las siguientes:

1. UI en la apertura del informativo

2. UI en los titulares del informativo

3. UI en las secciones del informativo

4. Tipos de UI

5. Duración de la UI

6. UI en la estructura del informativo

7. UI en la secuencia temporal del informativo

8. UI y foco territorial

9. UI y mención oral a la territorialidad

10. UI y representación del País Vasco en infografías y mapas

11. Protagonistas directos en la UI

12. Protagonistas indirectos en la UI

\subsection{Prueba de fiabilidad}

Para demostrar la fiabilidad de las categorías y poder así utilizar estas como base de la investigación se realizó una prueba piloto con tres codificadores independientes. Esta prueba tiene como fin verificar no solo la fiabilidad de las categorías, sino también su validez (Zabaleta, 1997: 119): "Cualquier escala e índice, cualquier procedimiento de medición, ha de tener estas cualidades: fiabilidad y validez. Por eso, cuando se crea una nueva escala índice, se ha de probar su idoneidad".

Los tres codificadores visionaron un informativo y rellenaron una ficha de datos, en la que las categorías y sub-categorías estaban dispuestas en columnas. En total, estas tres personas dispusieron del mismo tiempo para finalizar el trabajo. Cada codificador escribió en su ficha los códigos de las sub-categorías. Para ello, eligieron los códigos que, en su opinión, eran los apropiados a los contenidos y la estructura de cada unidad de información. Cada uno de los participantes en esta prueba realizó 129 codificaciones, lo que suma un cómputo de 387 codificaciones. Posteriormente se comprobó el porcentaje de coincidencias entre los resultados obtenidos de la clasificación efectuada por estos codificadores y se aplicó la prueba de fiabilidad de Holsti (Zabaleta, 1997: 226): 


\title{
Prueba de fiabilidad de Holsti
}

\author{
FIABILIDAD $\Longleftarrow \frac{2 \mathrm{M}}{\mathrm{N} 1+\mathrm{N} 2}$ \\ M: Número de codificaciones en que los dos codificadores coinciden \\ N1: Número de codificaciones realizadas por el primer codificador-K1- \\ N2: Número de codificaciones realizadas por el segundo codificador -K2-
}

Este estudio se vale de esta fórmula para analizar los resultados de la prueba piloto y verificar así el grado de fiabilidad del sistema de categorías establecido. En este caso la prueba se aplicará a los tres codificadores:

\section{Prueba de fiabilidad de Holsti}

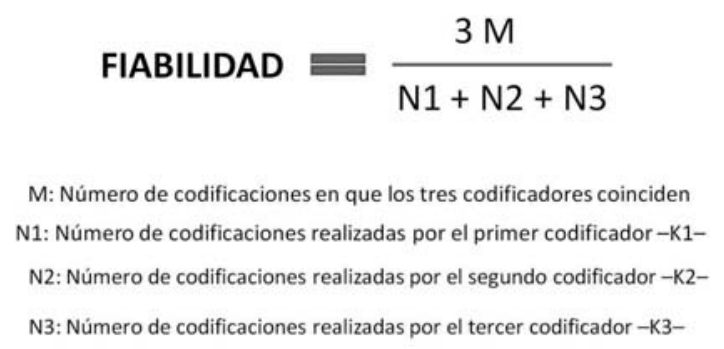

Tal y como sea indicado, cada participante realizó 129 actos de codificación, un total de 387. Los codificadores estuvieron de acuerdo en 125 de estas codificaciones. Por consiguiente, este sería el resultado final:

\section{Prueba de fiabilidad de Holsti}

$$
\begin{gathered}
\text { FIABILIDAD }=\frac{3 \mathrm{M}}{\mathrm{N} 1+\mathrm{N} 2+\mathrm{N} 3} \\
\text { FIABILIDAD }=\frac{3 \times 125}{129+129+129}=\frac{375}{387}=0,9689=97 \%
\end{gathered}
$$

Los resultados obtenidos deberán compararse con el porcentaje de fiabilidad para ver si alcanzan el mínimo exigido, que en este caso es el $90 \%$. Los resultados nos indican con claridad que el sistema utilizado en esta investigación es correcto y fiable, puesto que el grado de coincidencia entre los resultados de los tres codificadores es del $96,89 \%$ y supera con creces el $90 \%$ mínimo exigido. Por consiguiente el sistema de categorías creado para este trabajo es correcto, ya que ofrece un excelente nivel de 
fiabilidad (Zabaleta, 1997: 226): "Los metodólogos consideran que es idóneo lograr un porcentaje de fiabilidad entre los codificadores de al menos el $90 \%$ ".

\section{Creación y desarrollo de las categorías}

La creación de estas categorías se basa en la idea de que calibrar la importancia otorgada a la información política vasca en el Gaur Egun dependerá, en gran medida, del análisis del enfoque y de las características específicas de estas UI. El tipo de ítem, su duración y el lugar que ocupa en la escaleta del informativo, así como su distribución territorial, aportan datos objetivos para profundizar en esa investigación. A su vez, esto se complementa con la aprehensión del concepto geográfico, cultural y político que del País Vasco tienen las personas responsables de la gestión del ente público. Estos últimos datos, recabados mediante la realización de las entrevistas en profundidad con los responsables de los informativos de los años 2008 y 2010, corroborarán los resultados obtenidos mediante el análisis cuantitativo.

\subsection{UI en apertura, titulares y secciones del informativo}

Para cotejar y analizar la relevancia que la información política vasca tiene en Gaur Egun en un período determinado, se han cuantificado el número y el porcentaje de unidades derivadas de este tipo de noticias que abren el informativo o que se encuentran en la batería de titulares que se emite inmediatamente después de la apertura del mismo (categorías 1 y 2). También se ha tenido en cuenta el porcentaje de esas noticias en las secciones asignadas al informativo (categoría 3). A continuación se mencionan estas categorías con sus sub-categorías en la clasificación efectuada con el programa Excel. Los códigos correspondientes a cada una de ellas van entre paréntesis.

a) UI en las secciones del informativo (categoría 3):

- Política (POL): Sección que incluye las unidades de información que tratan toda actividad relativa al ejercicio del poder desde el gobierno, instituciones y estado, así como todo tipo de conflictos y luchas provenientes de su gestión y de la participación ciudadana en la res publica o esfera pública, tanto en el País Vasco como fuera de él.

- Sociedad (GIZ): Sección que incluye toda unidad de información acerca de los modos y las condiciones de las que disponen el ser humano y la sociedad para desarrollarse en el ámbito físico, psíquico, espiritual y material. Este apartado engloba las noticias relacionadas con los ámbitos de la salud, educación, vivienda, urbanismo, medio ambiente, infraestructuras, servicios sociales, tendencias y comportamientos humanos, investigación y ocio.

- Economía (EKO): Sección que incluye las noticias derivadas de las relaciones de producción, y también de los modos de crear, gestionar, distribuir y consumir los bienes derivados de esa actividad productiva. Es esta sección se clasifican las noticias del ámbito laboral y el mundo de la industria, banca y las finanzas. El apartado de la Bolsa queda fuera de estudio, ya que se ubica al final del informativo Gaur Egun, fuera del corpus y bien diferenciado por un spot publicitario.

- Cultura (KUL): Sección que incluye información concerniente a la creación artística, conocimiento humano y costumbres. 
- Curiosidades (BITX): Sección que incluye noticias curiosas y de carácter inusual sobre hechos o sucesos que se dan en el mundo, la sociedad o la naturaleza.

En este estudio se han analizado con especial interés las noticias de política vasca. Para delimitar ese terreno informativo se ha partido de la sub-categoría general de política y acotar así lo que se cataloga como tal:

- Política vasca: En este apartado se incluye toda aquella unidad de información relacionada con cualquier actividad, gestión, conflicto o lucha de índole política que afecte a cualquier territorio del País Vasco.

\subsection{UI: tipos y características}

La modalidad de ítem en que se presenta cada UI analizada, la duración de esta, su ubicación en la estructura del informativo y en el desarrollo temporal de este se analizan en los cuatro apartados siguientes (categorías 4, 5, 6 y 7)

b) Tipos de UI (categoría 4):

- Noticia o vídeo completo (AL): Unidad de información (UI) audiovisual totalmente independiente de la introducción del presentador del informativo, compuesta por la secuencia lógica de imágenes y la voz del periodista que elabora la noticia.

- Noticia con periodista ante la cámara (ALKA): Unidad de información (UI) audiovisual totalmente independiente de la introducción del presentador del informativo, compuesta por la secuencia lógica de imágenes y la voz del periodista que elabora la noticia. El propio periodista aparece ante las cámaras en una grabación realizada con anterioridad a la organización final de los componentes audiovisuales de la UI.

- Noticia con conexión (ALKO): Unidad de información (UI) audiovisual totalmente independiente de la introducción del presentador del informativo, compuesta por la secuencia lógica de imágenes y la voz del periodista que elabora la noticia. En esta unidad de información el periodista aparece ante las cámaras mediante una conexión en directo con el lugar en el que se desarrolla el hecho informativo y en el que él mismo se encuentra.

- Noticia con voz en 'off' y con presentador (ALOF): Unidad de información que se inicia con la aparición y el discurso informativo del presentador del noticiero para, a continuación, seguir su desarrollo con imágenes de la noticia citada con la voz de fondo del mismo presentador.

- Noticia con voz en 'off' (OFHU): Unidad de información presentada directamente como un vídeo con voz en 'off', sin la aparición física previa del presentador que la introduzca. En ocasiones, esa voz de fondo será del mismo presentador. Por el contrario, en otras ocasiones será otro periodista quien realice el comentario oral de la noticia.

- Declaraciones (ADI): Unidad de información compuesta por declaraciones de especial relevancia acerca de un hecho informativo determinado. En esta UI las únicas imágenes que aparecen son las de los protagonistas, los sujetos activos de esas declaraciones mientras están hablando, sin ningún otro elemento oral. Normalmente la unidad de información es introducida previamente por el presentador del informativo. 
c) Duración de la UI (categoría 5):

En esta categoría se mide la duración de las unidades de información presentes en el corpus del informativo. Este apartado cuenta con las siguientes sub-categorías: UI de 0-45 segundos (E); UI de 46-90 segundos (F); UI de 91-120 segundos (G) y UI de más de 120 segundos $(\mathrm{H})$.

d) UI en la estructura del informativo (categoría 6):

En esta categoría se analiza la disposición de las unidades de información en la secuencia del Gaur Egun. Las UI son ordenadas siguiendo el encadenamiento de estas dentro del corpus del informativo. Esta clasificación cuenta con cuatro sub-categorías: UI 0-9 (I); UI 10-18 (J); UI 19-27 (K) y 28+ (L)

e) UI en la secuencia temporal del informativo (categoría 7):

En esta categoría se clasifican las UI siguiendo el minutado real del informativo. El análisis no se realizará a partir del corpus, sino desde el mismo inicio del programa, para así poder medir el tiempo del informativo en su totalidad. También en este apartado son cuatro las sub-categorías creadas: UI entre los 0-10 minutos (M); UI entre los 11-20 minutos (N); UI entre los 21-30 minutos $(\mathrm{O})$ y UI a partir del minuto $31(\mathrm{P})$.

\subsection{Categorización de la territorialidad}

La visión de la territorialidad que proyecta el informativo es un elemento destacable a la hora de establecer las referencias geográficas del mismo, y el grado de proximidad afectiva que ello conlleva. Por citar un ejemplo: en los casos en que ese concepto de la territorialidad se cree desde una perspectiva nacionalista vasca, el País Vasco trascenderá los límites acotados por el estatuto de autonomía de Gernika, englobando los siete territorios que históricamente conforman Euskal Herria, País Vasco o País del Euskara: cuatro en el estado español y tres en el estado francés. En el supuesto contrario, aquel que se ciñe estrictamente a la legalidad constitucional, el País Vasco lo compondrán únicamente las provincias de Álava, Bizkaia y Gipuzkoa.

Con el objeto de captar y clasificar estas diferencias relacionadas estrictamente con el concepto de País Vasco se han creado tres apartados específicos para este análisis de contenido: el foco territorial de las unidades de información; la mención oral que se hace de la territorialidad y, por último, la representación del País Vasco en las infografías y mapas que aparecen en las UI del informativo. Cada una de estas tres categorías contiene unas determinadas sub-categorías, que se excluyen mutuamente. A continuación se mencionan estas categorías y sub-categorías con los códigos correspondientes utilizados en la clasificación efectuada con el programa Excel.

f) UI y foco territorial (categoría 8):

En esta categoría se nos indica el origen geográfico de una noticia. El foco territorial sitúa cada unidad de información relacionada con la política vasca en un espacio territorial concreto.

- Foco territorial Euskal Herria (L-EH)): Territorio formado por Álava, Bizkaia, Gipuzkoa, Navarra, Labourd, Baja Navarra y País de Soule en sentido lingüístico, cultural, histórico o político. 
- Foco territorial Hego Euskal Herria (L-HEH): Territorio formado por Álava, Bizkaia, Gipuzkoa, Navarra. Las elecciones generales en España, por ejemplo, entrarían en este apartado, ya que se celebran en las cuatro provincias.

- Foco territorial Euskal Autonomia Erkidegoa-Comunidad Autónoma Vasca (LEAE): Comunidad autónoma de la estructura político-administrativa del estado español que incluye los territorios de Álava, Bizkaia y Gipuzkoa. En esta sub-categoría se clasificarían las unidades de información relacionadas con noticias provenientes de las instituciones específicas de la administración autónoma: Gobierno Vasco, diputaciones forales, ayuntamientos, etc., etc., así como cualquier suceso o evento noticiable que se desarrolle en el ámbito geográfico de la Comunidad Autónoma Vasca (CAV).

- Foco territorial Nafarroako Foru Erkidegoa-Comunidad Foral Navarra (L-NFE): Comunidad autónoma de la estructura político-administrativa del estado. En esta subcategoría se clasificarían las unidades de información relacionadas con noticias provenientes de las instituciones específicas de la administración autónoma: Gobierno de Navarra, diputación, ayuntamientos, etc., etc., así como cualquier suceso o evento noticiable que se desarrolle en el ámbito geográfico de la Comunidad Foral Navarra.

- Foco territorial Ipar Euskal Herria (L-IEH): Territorio del estado francés formado por las provincias de Labourd, Baja Navarra y País de Soule, situado en el Departamento de los Pirineos Atlánticos. En esta sub-categoría se clasifican las unidades de información relacionadas con noticias provenientes de las instituciones situadas en este territorio, así como cualquier suceso o evento noticiable que se desarrolle en ese mismo ámbito geográfico.

- Foco territorial España (L-ESP): Todo territorio dentro de las fronteras políticoadministrativas del estado español. En esta sub-categoría se excluyen las provincias de Álava, Bizkaia, Gipuzkoa y Navarra, ya que la información concerniente a las mismas se encuentra clasificada en los apartados codificados como L-EH, L-HEH, LEAE y L-NFE, siempre dependiendo de los criterios que se razonarán en el apartado Conclusiones de este trabajo.

- Foco territorial Francia (L-FR): Todo territorio dentro de las fronteras político-administrativas del estado francés. En esta sub-categoría se excluyen las provincias del Labourd, Baja Navarra y el país de Soule, ya que la información concerniente a las mismas se encuentra clasificada en el apartado codificado como L-IEH, siempre dependiendo de los criterios que se razonarán en el apartado Conclusiones de este trabajo.

g) UI y mención oral a la territorialidad (categoría 9):

En esta categoría se analiza como los periodistas denominan al País Vasco al referirse oralmente a este, sea en la presentación de las noticias, sea en la elaboración y en la edición de las unidades de información. Este apartado cuenta con las siguientes sub-categorías:

- Euskal Herria (EH)): Territorio formado por Álava, Bizkaia, Gipuzkoa, Navarra, Labourd, Baja Navarra y País de Soule en sentido lingüístico, cultural, histórico o político.

- Hego Euskal Herria (HEH): Territorio formado por Álava, Bizkaia, Gipuzkoa, Navarra. 
- Euskadi o Euskal Autonomia Erkidegoa-Comunidad Autónoma Vasca (EAE): Comunidad autónoma de la estructura político-administrativa del estado español que incluye los territorios de Álava, Bizkaia y Gipuzkoa ${ }^{1}$.

- Navarra o Nafarroako Foru Erkidegoa-Comunidad Foral Navarra (NFE): Comunidad autónoma de la estructura político-administrativa del estado español.

- Ipar Euskal Herria (IEH): Territorio del estado francés formado por las provincias de Labourd, Baja Navarra y País de Soule, situado en el Departamento de los Pirineos Atlánticos.

h) UI y representación del País Vasco en infografías y mapas (categoría 10):

En esta categoría se analizan las infografías y mapas que toman como referencia el País Vasco. Se establecen tres sub-categorías: País Vasco con las siete provincias y sin separación administrativa gráfica (IEHO); Comunidad Autónoma Vasca y Comunidad Foral Navarra sin separación administrativa gráfica (IHEH); Comunidad Autónoma Vasca y Comunidad Foral Navarra con separación administrativa gráfica (IEUS).

Desde la antigüedad, el poder ha sido consciente de que la cartografía y, sobre todo, su uso son elementos muy útiles para ayudar a la construcción del imaginario de los pueblos y la cohesión de la sociedad en torno a un referente geográfico determinado (Basterretxea, 2000: 195): "Desde épocas remotas los estados y los pueblos sin estado se percataron del valor estratégico de los mapas. El valor añadido de estos fue percibido tanto por el poder que tenía bajo sus dominios un determinado territorio, como por los pueblos que anhelaban construir y delimitar un espacio propio".

Así pues, la televisión es un medio eficaz para insertar esa representación geográfica de la visión territorial que una colectividad tiene de sí misma o aquella realidad que el poder quiere imponer o afianzar (Ferrés, 1994: 79): "Nuestra imagen de la realidad es básicamente la que nos ofrecen los media, y sobre todo la televisión. De ahí la importancia de su control social".

\subsection{Protagonistas políticos}

Esta categoría y la siguiente son las que clasifican como protagonistas directos o protagonistas indirectos a los agentes o actores de la política vasca. Los protagonistas son miembros de cualquier partido u opción política vasca, y aparecen en el informativo dando su opinión sobre algún hecho de la actualidad política. Estas dos categorías cuentan con las sub-categorías correspondientes a los partidos políticos de ámbito vasco. Con ello se pretende comparar el protagonismo de los agentes políticos vascos en los informativos de ETB durante el mandato de Ibarretxe y el de López.

Este apartado pretende verificar en qué medida se ve reflejada la pluralidad de la sociedad vasca en el contenido del informativo. El noticiero no puede ofrecer una imagen exacta y objetiva de la realidad, asegura Fiske, pero debe dar cabida a todas

${ }^{1}$ El estatuto de autonomía de Gernika da el nombre oficial de Euskadi al territorio autónomo compuesto por las provincias de Álava, Bizkaia y Gipuzkoa, por lo que ese término se utiliza también como sinónimo de Comunidad Autónoma Vasca en el informativo. 
sus voces para que la ciudadanía tenga la posibilidad de "discutir" sobre los distintos puntos de vista imperantes en la sociedad (Fiske,1987: 307-308): "En una democracia progresista la noticia [...] debería nombrar todas sus voces y debería abrir su texto para invitar a relaciones de interpretación más productibles".

i) Protagonistas directos en la UI (categoría 11):

El protagonista directo es el partido cuyo miembro aparece hablando durante un determinado tiempo ante las cámara, como parte de una UI, generalmente un ítem de tipo noticia o vídeo completo. Sus palabras se oyen con nitidez, ya que no se les superpone ningún otro audio. Al estar insertadas en una UI más amplia en su duración que el tiempo específico de la alocución, las palabras de estos protagonistas no pueden ser consideradas como un ítem del tipo declaraciones, pues no abarcan todo el tiempo de duración de esa unidad de información.

j) Protagonistas indirectos en la UI (categoría 12):

En esta categoría entran los partidos políticos cuyos dirigentes o miembros son mencionados por otros representantes políticos en declaraciones antes las cámaras de televisión que luego son insertadas en una UI, generalmente una noticia o un vídeo completo. Son protagonistas indirectos, ya que no aparecen de una manera visual en la pantalla, sino mediante una referencia efectuada por otro político que sí aparece en la noticia. Un partido político puede ser protagonista directo e indirecto en la misma unidad de información. Por ejemplo: un miembro del partido político A aparece en la pantalla dando su opinión sobre un tema de actualidad. A continuación, y siempre en la misma UI, el representante de otra formación política (B) opina sobre ese asunto, y se refiere a la postura que el partido A ha defendido al respecto. El partido A es, pues, protagonista directo e indirecto; el partido B, solo protagonista indirecto.

\section{Conclusiones}

El proceso de crear y definir las categorías y sub-categorías específicas para realizar el análisis cuantitativo de este trabajo y la casuística de estas nos muestran diversas conclusiones que, pese a extraerse de este estudio, son extrapolables al ámbito de la categorización de los contenidos de un informativo televisivo.

- Las categorías diseñadas para la investigación cuantitativa deben caracterizarse por ser concretas y univalentes, y acotar con claridad el área que se pretende analizar. Por ejemplo, la definición de la categoría Política en este estudio tiene como base "toda actividad relativa al ejercicio del poder desde el gobierno, instituciones y estado, así como todo tipo de conflictos y luchas provenientes de su gestión y de la participación ciudadana en la res publica o esfera pública". Esta definición de aplicación universal será el principio del que se partirá para definir la política vasca en particular como "toda unidad de información relacionada con cualquier actividad, gestión, conflicto o lucha de índole política que afecte a cualquier territorio del País Vasco". Con ello queda claro que no solo se analizará en este apartado la información política con origen geográfico vasco, sino aquella fuera de este, pero que tenga como eje el País Vasco o cuyas consecuencias puedan atañer también a sus ciudadanos. Por ejem- 
plo, una noticia sobre un pleno en el Parlamento español en el que se discuta sobre el concierto económico vasco y las posibles competencias del Gobierno vasco para defender su vigencia ante las autoridades europeas en Bruselas será clasificada como UI de política vasca, a pesar de que geográficamente esa noticia haya acaecido en Madrid. Será, pues, una UI de política vasca con foco territorial España (L-ESP).

- Las sub-categorías creadas para el análisis cuantitativo han de ser definidas con gran exactitud y extrema precisión, de tal manera que devengan mutuamente excluyentes. Estas características se reflejan en todos los apartados del estudio. Como muestra, valgan algunas de las categorías que se han propuesto en el análisis de la territorialidad (categorías 8, 9 y 10). En el apartado del análisis de la mención oral al País Vasco se emplea, por una parte, el término Euskal Herria para designar el territorio de habla vasca a ambos lados de los Pirineos. Por otra parte, tenemos la palabra Euskadi, como equivalente a Comunidad Autónoma Vasca y restringida a este espacio. En este sentido, es de reseñar que la lengua tiene especial relevancia a la hora de designar el territorio, ya que en euskara, normalmente, el concepto de Euskal Herria abarcaría todo el territorio de lengua vasca, pues es así cómo está construido en el subconsciente del vascoparlante. En castellano, en cambio, País Vasco es utilizado frecuentemente para designar las provincias que componen la CAV: Álava, Bizkaia y Gipuzkoa.

- En los casos en que determinados contenidos puedan ser susceptibles de crear confusión a la hora de clasificarlos en una determinada categoría se procederá a razonar su inclusión en ese apartado, para así evitar toda ambigüedad e indefinición que obstaculicen el trabajo. Podemos encontrar un ejemplo de esto en el tratamiento que en este trabajo se otorga a la información relacionada con los conflictos laborales. Por definición, el área del trabajo y los conflictos laborales pertenecen a la sección de Economía y serán insertados en esta categoría. Sin embargo, si un conflicto laboral trasciende el ámbito local de las relaciones de producción de la empresa y sus consecuencias afectan a la gran parte de la población, será analizado en la categoría de Sociedad. Esto es lo que sucede con las huelgas de los sectores de la enseñanza y de la sanidad.

- Lo mismo sucede en el caso de ciertas sub-categorías, sobre todo en el encaje geográfico de algunas unidades de información en las que no existe referencia concreta. Un ejemplo: en el caso del concierto del grupo Oskorri en Bilbao, el foco territorial se situará en la Comunidad Autónoma Vasca. Por el contrario, la unidad de información acerca del nuevo disco producido por el cantante Benito Lertxundi se clasificará en el apartado de Euskal Herría, ya que en esa UI no se nos especifica ninguna referencia geográfica definida. Es un disco del ámbito de la cultura vasca que se distribuirá por todo el País Vasco y, por consiguiente, lo encuadraremos en esta última categoría.

\section{Referencias bibliográficas}

BASTERRETXEA, Jose Inazio (2000): "Lurraldetasuna: Euskal Herriaren formaaniztasun mediatikoa", en Nor Ikerketa Taldea, Hedabideak eta Euskal Herria. Bilbao, Udako Euskal Unibertsitatea, pp. 155-197 
BERELSON, Bernard (1962): Content Analysis in Communication Research. Glencoe, Ill, Free Press

DIJK, Teun A.van (1990): La noticia como discurso. Comprensión, estructura y producción de la información. Barcelona, Paidós

FERRÉS, Joan (1994): Televisión y educación. Barcelona, Paidós Ibérica

FISKE, John (1987): Television Culture. London, Routledge

GALEANO MARÍN, María Eumelia (2004): Diseño de proyectos de investigación cualitativa. Medellín, Fondo editorial universidad EAFIT

HARTLEY, John (1992): Tele-ology: Studies in Television. London, Routledge

HOLSTI, Ole Rudolf (1969): Content Analysis for the Social Sciences and Humanities. Reading, MA, Addison-Wesley

MARTÍN SABARÍS, Rosa María (1999): La organización informativa y los procesos de producción de la noticia. La información diaria en Euskal Telebista. Bilbao, Universidad del País Vasco, Servicio de Publicaciones.

MARTIN SERRANO, Manuel (1981): "La influencia social de la televisión (I)". Revista Española de Investigaciones Sociológicas, núm. 1, Madrid, pp. 39-55.

ZABALETA, Iñaki (1997): Komunikazioaren ikerkuntzarako metodologia. Bilbao, Udako Euskal Unibertsitatea. 